\title{
Developmental Changes in Short-Term Plasticity at the Rat Calyx of Held Synapse
}

\author{
Tom T. H. Crins, ${ }^{1,2}$ Silviu I. Rusu, ${ }^{1}$ Adrian Rodríguez-Contreras, ${ }^{1}$ and J. Gerard G. Borst ${ }^{1}$ \\ Departments of ${ }^{1}$ Neuroscience and ${ }^{2}$ Otorhinolaryngology and Head and Neck Surgery, Erasmus MC, University Medical Center Rotterdam, 3015 GE \\ Rotterdam, The Netherlands
}

The calyx of Held synapse of the medial nucleus of the trapezoid body functions as a relay synapse in the auditory brainstem. In vivo recordings have shown that this synapse displays low release probability and that the average size of synaptic potentials does not depend on recent history. We used a ventral approach to make in vivo extracellular recordings from the calyx of Held synapse in rats aged postnatal day 4 (P4) to P29 to study the developmental changes that allow this synapse to function as a relay. Between P4 and P8, we observed evidence for the presence of large short-term depression, which was counteracted by short-term facilitation at short intervals. Major changes occurred in the last few days before the onset of hearing for air-borne sounds, which happened at P13. The bursting pattern changed into a primary-like pattern, the amount of depression and facilitation decreased strongly, and the decay of facilitation became much faster. Whereas short-term plasticity was the most important cause of variability in the size of the synaptic potentials in immature animals, its role became minor around hearing onset and afterward. Similar developmental changes were observed during stimulation experiments both in brain slices and in vivo following cochlear ablation. Our data suggest that the strong reduction in release probability and the speedup of the decay of synaptic facilitation that happen just before hearing onset are important events in the transformation of the calyx of Held synapse into an auditory relay synapse.

\section{Introduction}

The medial nucleus of the trapezoid body (MNTB) functions as an inverting relay in the auditory brainstem. The synaptic transmission across the MNTB has to be both fast and reliable. These requirements are met by a giant excitatory axosomatic synapse: each principal neuron is contacted by a single calyx of Held, which originates from globular bushy cells in the anteroventral cochlear nucleus (Schneggenburger and Forsythe, 2006). By virtue of its many release sites, the adult calyx can drive its principal neuron at high frequencies for sustained periods (Guinan and Li, 1990). Even though there are activity-dependent changes in, for example, the synaptic delay (Mc Laughlin et al., 2008; Tolnai et al., 2009), these changes are typically small compared with upstream changes (Lorteije and Borst, 2011).

Because of the large size of this synapse, juxtacellular (loosepatch) recordings from principal neurons are characterized by the presence of a complex waveform, which consists of a prespike that signals the presynaptic action potential and a postsynaptic

Received April 20, 2011; revised June 8, 2011; accepted June 16, 2011.

Author contributions: T.T.H.C., S.I.R., and J.G.G.B. designed research; T.T.H.C., S.I.R., and A.R.-C. performed research; T.T.H.C., S.I.R., and J.G.G.B. analyzed data; T.T.H.C. and J.G.G.B. wrote the paper.

This work was supported by an FP6 European Union grant (EUSynapse, LSHM-CT-2005-019055), the Heinsius Houbolt fund, Earth and Life Sciences-Netherlands Organisation for Scientific Research (Moving Vesicles, 814.02.004), and SenterNovem, The Netherlands (Neuro-Bsik, BSIK 03053). We thank Hans van der Burg for advice on stimulation electrodes.

Correspondence should be addressed to J. Gerard G. Borst, Department of Neuroscience, Erasmus MC, University Medical Center Rotterdam, D. Molewaterplein 50, 3015 GE Rotterdam, The Netherlands. E-mail: g.borst@erasmusmc.nl.

A. Rodríguez-Contreras' present address: Department of Biology, City College of New York, New York, NY 10031. DOI:10.1523/JNEUROSCI.1995-11.2011

Copyright $\odot 2011$ the authors $\quad 0270-6474 / 11 / 3111706-12 \$ 15.00 / 0$ waveform, which consists of the extracellularly recorded EPSP (eEPSP) and, when the eEPSP is suprathreshold, the extracellularly recorded postsynaptic action potential (eAP) (Guinan and Li, 1990; Lorteije et al., 2009). We previously showed that the eEPSP provides a measure for the strength of synaptic transmission. Using both in vivo juxtacellular and whole-cell recordings from the mouse calyx of Held synapse, we found that this synapse shows little or no evidence for the presence of short-term plasticity (STP) (Lorteije et al., 2009).

Even though this finding was in agreement with the tonic, relay aspect of its function, it was nevertheless unexpected. Because of the accessibility of the presynaptic terminal and its postsynaptic partner to patch-clamp recordings in slices (Forsythe, 1994; Borst et al., 1995), synaptic transmission at the calyx of Held synapse has been well studied. One of the main findings was that this synapse displays several forms of STP, including shortterm facilitation and short-term depression, and the mechanisms underlying these different forms of STP have been well characterized (von Gersdorff and Borst, 2002). The large discrepancy between results obtained in vivo and in vitro is incompletely understood. One contributing factor is that the release probability of the mature calyx of Held synapse is much lower in vivo than previous in vitro estimates (Lorteije et al., 2009). The developmental decrease of release probability (Taschenberger and von Gersdorff, 2000; Iwasaki and Takahashi, 2001; Taschenberger et al., 2002), the lower calcium concentration in vivo (Lorteije et al., 2009), and tonic depression owing to spontaneous activity (Hermann et al., 2007) may all contribute to this discrepancy. Even though the low release probability provides an explanation for the apparent lack of short-term depression, it does not explain 
why high-frequency activity does not lead to pronounced shortterm facilitation under these circumstances (Borst et al., 1995). To better understand the synaptic mechanisms that allow the calyx of Held synapse to be both precise and reliable, we studied changes in firing pattern, synaptic speed, reliability, and STP between postnatal day $4(\mathrm{P} 4)$ and $\mathrm{P} 29$.

\section{Materials and Methods}

Methods

Animals. All experiments were conducted in accordance with the European Communities Council Directive and were approved by the Animal Ethics Committee of the Erasmus MC.

The day of birth is defined as P0. A total of 79 Wistar rats of either sex were anesthetized with isoflurane (induction at $5 \%$, maintenance at $\sim 1 \%$ ) and placed in the supine position. Rectal temperature was maintained between $37^{\circ} \mathrm{C}$ and $38^{\circ} \mathrm{C}$ with a homeothermic blanket system (Stoelting). In posthearing animals, the external ear canal was filled with silicone gel to reach maximal conductive hearing loss. Following laryngectomy, the animal was intubated and mechanically ventilated. Animals between P4 and P15 were ventilated with a MiniVent (type 845; Harvard Apparatus) at a frequency of $\sim 80$ breaths/min; stroke volume was $7 \mu \mathrm{l} / \mathrm{g}$ body weight. Animals between P16 and P29 were ventilated with a Small Animal Ventilator (KTR-5; Harvard Apparatus) at a frequency of 64 breaths/min; end-inspiratory pressure was $\sim 12 \mathrm{~cm} \mathrm{H}_{2} \mathrm{O}$ (maximum, 20 $\mathrm{cm} \mathrm{H}_{2} \mathrm{O}$ ); the inspiration/expiration ratio was 44:56. Arterial oxygen saturation and heart rate were monitored using a MouseOx (STARR Life Sciences). The left MNTB was reached via a ventral approach, as previously described (Rodríguez-Contreras et al., 2008). Typically, the location of the MNTB was $400-500 \mu \mathrm{m}$ rostrally from the left anterior inferior cerebellar artery and 400-450 $\mu \mathrm{m}$ laterally from the basilar artery. In some experiments with relatively large surface movements, agar was applied on the surface before recording.

In vivo electrophysiology. In vivo juxtacellular (loose-patch) recordings were made as previously described (Lorteije et al., 2009). Glass micropipettes (3.5-5.0 M $\Omega$ ) were filled with a solution containing the following (in mM): $135 \mathrm{NaCl}, 5.4 \mathrm{KCl}, 1 \mathrm{MgCl}_{2}, 1.8 \mathrm{CaCl}_{2}$, and 5 HEPES, pH 7.2. When passing the brain surface, high positive pressure ( $\sim 300$ millibars) was used, which was lowered to $\sim 12$ millibars when searching for cells, and to 0 millibars during recordings.

In vivo stimulation experiments were performed as previously described (Tritsch et al., 2010). Briefly, the location of the MNTB was first ascertained by making a juxtacellular recording from a spontaneously active unit with a complex waveform. Subsequently, spontaneous activity was abolished by mechanically ablating the contralateral cochlea with tweezers after drilling a hole in the bulla and, in the case of the youngest animals, removing the mesenchyme in the bullar cavity. A bipolar Pt/Ir electrode (MicroProbes for Life Science) was inserted at the contralateral side, below the basilar artery. Afferent fibers were stimulated $(<0.5 \mathrm{~mA}$, $0.1 \mathrm{~ms}$ ) using a stimulus isolator (A385, World Precision Instruments). The stimulus protocol consisted of paired-pulse stimuli with intervals ranging from 2 to $2400 \mathrm{~ms}$, which was repeated between 6 and 10 times, or a custom made in vivo-like stimulation protocol resembling the spontaneous firing pattern of a P5 animal. The in vivo-like stimulation protocol consisted of a randomized sequence of 450 intervals ranging from 3 $\mathrm{ms}$ to $9 \mathrm{~s}$, which were drawn from three lognormal distributions with preferred intervals at $\sim 10,100$, and $1000 \mathrm{~ms}$ (see Fig. $6 A, B$ ). The protocol was applied once and had a total duration of $\sim 4 \mathrm{~min}$.

Data were acquired with an Axopatch 200B amplifier (MDS Analytical Technologies) in fast current-clamp mode, filtered with a low-pass fourpole Bessel filter, and sampled at an interval of $20 \mu$ s with a Digidata 1320A.

Auditory brainstem response. Before surgery, the auditory brainstem response (ABR) was measured to obtain hearing thresholds in 17 animals at $4,8,16$, and $32 \mathrm{kHz}$, as described previously (van Looij et al., 2004). Rats were anesthetized with ketamine/xylazine $(0.08 \mathrm{ml} / 10 \mathrm{~g}$ body weight of a solution containing $0.12 \%$ xylazine and $0.8 \%$ ketamine in $0.9 \%$ $\mathrm{NaCl})$. The tone repetition rate was $80 \mathrm{~Hz}$. Maximum tone pip intensities were $120 \mathrm{~dB}$ SPL at $4-16 \mathrm{kHz}$ and $105 \mathrm{~dB}$ SPL at $32 \mathrm{kHz}$.
In vitro whole-cell slice recordings. MNTB slices were prepared as described previously (Habets and Borst, 2007; Lorteije et al., 2009). In short, P4-P6 or P13-P16 Wistar rats were decapitated under deep isoflurane anesthesia, and the isolated brainstem was submerged in ice-cold oxygenated artificial CSF (aCSF) containing the following (in mM): 125 $\mathrm{NaCl}, 2.5 \mathrm{KCl}, 3 \mathrm{MgSO}_{4}, 0.1 \mathrm{CaCl}_{2}, 1.25 \mathrm{NaH}_{2} \mathrm{PO}_{4}, 0.4$ ascorbic acid, 3 myo-inositol, 2 pyruvic acid, 25 D-glucose, $25 \mathrm{NaHCO}_{3}$ (Merck), pH 7.4 with carbogen. Coronal slices containing the MNTB were cut at a thickness of $150-200 \mu \mathrm{m}$. After incubation for $30 \mathrm{~min}$ at $37^{\circ} \mathrm{C}$, slices were transferred to the recording chamber of an upright microscope (BX-50, Olympus). Recordings were performed at physiological temperature (35$37^{\circ} \mathrm{C}$ ), and slices were continuously perfused with carbogenated aCSF with the same composition as the slicing solution, except that the concentration of $\mathrm{CaCl}_{2}$ was either 0.6 or $1.2 \mathrm{~mm}$ and the $\mathrm{MgSO}_{4}$ concentration was $1 \mathrm{~mm}$. MNTB afferents were stimulated using a bipolar electrode (FHC Inc.) positioned at the midline or half-way between the midline and the MNTB. In whole-cell experiments, borosilicate glass electrodes (2.5-5.5 $\mathrm{M} \Omega$ ) were filled with intracellular solution containing the following (in $\mathrm{mm}$ ): K-gluconate 125, $\mathrm{KCl} 20, \mathrm{Na}_{2}$-phosphocreatine 10, $\mathrm{Na}_{2}$-GTP 0.3, Mg-ATP 4, EGTA 0.5, HEPES 10, pH 7.2; extracellular electrodes were filled with aCSF. Voltages were compensated for the liquid junction potential $(-11$ $\mathrm{mV}$ ) between the pipette solution and the aCSF. The holding potential was $-80 \mathrm{mV}$. Series resistance $(<15 \mathrm{M} \Omega$ ) was compensated by $95-98 \%$ with a lag of 7-10 $\mu$ s during voltage-clamp recordings. Voltage-clamp and currentclamp data were acquired using an Axopatch 200B amplifier and were filtered at $2-10 \mathrm{kHz}$ with a low-pass four-pole Bessel filter. Data were digitized at intervals of $16-25 \mu \mathrm{s}$.

The same two stimulus protocols were used in the slice electrophysiology as in the in vivo electrophysiology described above. The pairedpulse protocol was run in voltage-clamp mode; the in vivo-like protocol was run in both voltage-clamp and current-clamp modes. These three configurations were tested at both 1.2 and $0.6 \mathrm{~mm}$ calcium, for a total of up to six different stimulus protocols on the same cell, depending on the stability of the recording.

To determine the origin of the extracellular waveform at the rat calyx of Held synapse, we made simultaneous intracellular and extracellular slice recordings in P6-P9 rats, as described previously (Lorteije et al., 2009). Correlation between amplitudes of postsynaptic events in wholecell voltage-clamp or current-clamp and extracellular current-clamp recordings was calculated from the responses evoked by afferent stimulation, with stimulus trains ranging from 10 to $200 \mathrm{~Hz}$.

\section{Analysis}

Data were analyzed with custom-written Igor procedures (Igor Pro 6.0.2.0; WaveMetrics) running within the NeuroMatic environment (version 2.00, kindly provided by Dr. J. Rothman, University College London, London, UK).

Measuring EPSC amplitudes. EPSC amplitudes were measured as the difference between peak and baseline. To estimate the baseline, a doubleexponential function was fitted to the decay phase of each EPSC. The extrapolated value of the fitted function at the time of the next EPSC peak was taken as the baseline. In case the amplitude of the stimulus artifact at the start of the EPSC was $>5 \%$ of the peak EPSC amplitude, a doubleexponential fit to the decay phase of the stimulus artifact was used instead to estimate the baseline.

Analysis of complex waveforms. Complex waveforms were analyzed as previously described (Lorteije et al., 2009). Whole-cell current-clamp recordings were differentiated before analysis. The minimum signal-tonoise ratio, which was defined as the ratio of the mean EPSP amplitude and the SD of the baseline, was 7. On average, it was $20 \pm 2(n=63)$ in the spontaneous in vivo recordings.

Short-term plasticity model. The relation between the size of the eEPSP and the inter-EPSP interval was described with a simple model for STP (Varela et al., 1997). In the presence of both facilitation and depression, the eEPSP amplitude depended on the availability of a depletion factor, $D$, which was constrained to be between 0 and 1 , and a facilitation factor, $F$. With each event, the depletion factor depleted with fraction $d$, which was also constrained to be between 0 and 1 , as follows:

$$
D \rightarrow d D
$$


Following the event, $D$ recovered exponentially from depletion with time constant $\tau$, as follows:

$$
\tau_{D} d D / d t=1-D
$$

With each event, the facilitation factor $F$ increased with a certain amount, $f$, as follows:

$$
F \rightarrow F+f
$$

Following the event, $F$ recovered exponentially analogously to $D$.

The amplitude $A$ of the eEPSP depended in a multiplicative fashion on the availability of the two resources, as follows:

$$
A=A_{\text {inf }} F D
$$

where $A_{\text {inf }}$ is the amplitude of the eEPSP after a very long interval. All EPSP amplitudes from a given experiment were fit at once to incorporate cumulative effects. Fits were evaluated by plotting predicted against measured sizes to look for systematic deviations. Especially in the in vivo spontaneous data before hearing onset, the interval distributions were inhomogeneous. We therefore used inverse probability weighting (Horvitz and Thompson, 1952); events were weighted by the square root of the local sparseness. For each event, its local sparseness was defined as the inverse of the total number of events in the neighborhood of each event. We defined 0.5 decade for the logarithmically transformed intervals as the neighborhood. To evaluate the goodness-of-fit of the three models, facilitation alone, depression alone, and both facilitation and depression, a Pearson's $r$ value between fitted and measured amplitudes was calculated. Its square, $r^{2}$, sometimes called the coefficient of determination, is a measure for the proportion of the amplitude variance that is accounted for by the STP model. We accepted an extra component (e.g., facilitation) if the explained variance increased by at least $2.5 \%$.

EPSP amplitudes were linearly detrended before fitting the STP model if a linear regression could explain $>10 \%$ of the variance in their amplitudes (5.9\% of fits).

To estimate the recovery from spike depression, the same model was used, except there was no facilitation factor and no weighting (Lorteije et al., 2009). In contrast to Lorteije et al. (2009), recovery from depression was set to start instantaneously.

In 10 cells that had postsynaptic failures and showed both facilitation and depression, we estimated the impact of synaptic facilitation on reliability by calculating the increase in spike failures after subtracting the estimated contribution of facilitation. This estimate was obtained from the fit of the measured eEPSP amplitudes with the model that included both facilitation and depression. The fit function calculates predicted amplitudes for each measured eEPSP. In addition, we calculated what the predicted amplitudes would be for the same model parameters, except that the facilitation was omitted. For each measured eEPSP, the difference between the amplitude prediction with and without facilitation provides an estimate for the contribution of facilitation, given the interval history of that eEPSP. We then calculated the percentage of eEPSPs that became subthreshold after subtraction of these estimates from the measured amplitudes. An uncertainty in this procedure is the threshold for triggering an AP, since there were generally no failures at short intervals, when synaptic facilitation has the largest impact. We therefore assumed that the threshold that was measured at longer intervals could also be used at short event intervals in the same cell. This assumption neglects the (opposite) effects of spike depression and EPSP summation (Lorteije et al., 2009).

Statistical analysis. Data are given as the mean \pm SE, except when noted otherwise. Differences between two means were assessed by Student's $t$ test.

\section{Results}

\section{Hearing onset occurs at $\sim \mathrm{P} 13$}

We studied developmental changes in synaptic transmission at the rat calyx of Held synapse between P4 and P29. To be able to relate developmental changes in firing pattern and synaptic transmission to the maturation of the peripheral auditory system, we assessed the status of the external auditory meatus by visual inspection at the start of each experiment. In all 42 animals in the age range $\mathrm{P} 4-\mathrm{P} 12$, the external auditory meatus was still closed, whereas in 2 of 5 P13 animals and all 32 animals in the age range P14-P29, including 3 P14 animals, it had opened. In addition, we measured the responses to air-borne sounds using ABRs in 17 animals in the age range P6-P18 before surgery. No responses were found in P6-P11 animals $(n=7)$. At P13, the two animals with the closed external auditory meatus showed responses only at $4 \mathrm{kHz}$ and only at very high intensities (100-115 dB SPL). Two other P13 animals showed responses not only at $4 \mathrm{kHz}$, but also at both 8 and $16 \mathrm{kHz}$; thresholds ranged from 85 to $115 \mathrm{~dB}$. At P14, thresholds were $80-100 \mathrm{~dB}$ at $4-16 \mathrm{kHz}$; still, no responses were measured at $32 \mathrm{kHz}(n=3)$. At P17-P18, thresholds at $4-16 \mathrm{kHz}$ were $20-50 \mathrm{~dB}$; at $32 \mathrm{kHz}$, they were $45-80 \mathrm{~dB}(n=3)$. Our data thus indicate that onset of air-borne sound hearing starts around $\mathrm{P} 13$, in general agreement with previous studies in the rat, which found hearing onset to occur between P10 and P14 (Jewett and Romano, 1972; Uziel et al., 1981; Blatchley et al., 1987; Rybak et al., 1992; Geal-Dor et al., 1993). The opening of the ear canal was a good predictor for hearing onset, especially at $8-16 \mathrm{kHz}$, even though other factors such as the maturation of the middle ear and the endocochlear potential may be functionally more important (Jewett and Romano, 1972; Woolf and Ryan, 1988; Rybak et al., 1992).

\section{Firing pattern changes from bursting to primary like just before hearing onset}

To study the developmental changes in synaptic transmission at the rat calyx of Held synapse, rats were anesthetized and the MNTB was reached via a ventral approach. All in vivo recordings were made in the juxtacellular (loose-patch) configuration, allowing unambiguous identification of single-unit recordings from principal neurons based on their characteristic complex waveform (Figs. $1 A-C, 2 A$ ). Before hearing onset, principal neurons fired bursts of action potentials (Fig. 1A) (Sonntag et al., 2009); these bursts were triggered by spontaneous calyceal inputs at preferred intervals of $\sim 10,100-300$, and $>1000 \mathrm{~ms}$ (Fig. 1A), in agreement with our previous findings (Tritsch et al., 2010). At P11, just before hearing onset, cells still showed a bursting firing pattern, but long intervals became rare (Fig. $1 B$ ). The adult spontaneous, primary-like firing pattern is illustrated in Figure $1 C$. An overview of the spontaneous firing patterns of 140 cells between P4 and P29 is shown in Figure $1 D$, illustrating the transition from a bursting pattern before hearing onset to a primary-like firing pattern in the young adult, which largely happened between P9 and P11 (i.e., before hearing onset). In most units, the signal-tonoise ratio was sufficient to verify that all postsynaptic events were preceded by a prespike, suggesting that the calyx drove the spontaneous activity of principal neurons throughout this developmental period. The developmental decrease in the variability was reflected by a decrease in the coefficient of variation $(\mathrm{CV})$ of the event intervals (Fig. $1 E$ ). In 4-6-day-old animals, the CV was on average $3.06 \pm 0.30(n=20)$, whereas in young-adult animals (P26-P29), it had decreased to a value of $0.90 \pm 0.05(n=12)$, close to the prediction for a primary-like firing pattern (Heil et al., 2007). The mean firing rates were on average $0.69 \pm 0.11 \mathrm{~Hz}$ $(n=42)$ in recordings from $4-6$-day-old animals (Fig. $1 F)$; after hearing onset, mean frequencies were quite variable (KoppScheinpflug et al., 2008), but generally much higher than before hearing onset. Average firing frequencies in young-adult animals (P26-P29) were $21.8 \pm 8.6 \mathrm{~Hz}(n=12)$. Several factors are probably responsible for the observed changes, including matu- 
A


D



B


E

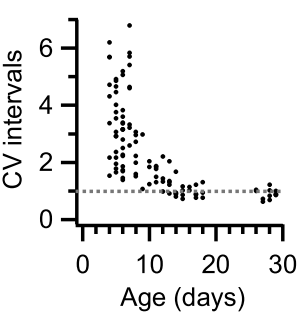



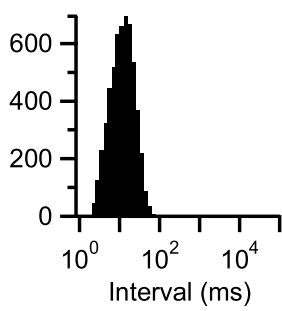

$\mathbf{F}$



Figure 1. Developmental changes in firing pattern. $\boldsymbol{A}$, Example of bursting firing pattern of a principal neuron from the MNTB of a $\mathrm{P} 5$ rat during an in vivo juxtacellular recording. Bottom, Complex waveforms at higher time resolution, consisting of a prespike, and followed by an eEPSP and the postsynaptic action potential (eAP). The bottom panel shows the interevent interval histogram. Preferred intervals cluster around $10 \mathrm{~ms}$, a few hundred milliseconds, and $10 \mathrm{~s}$. $\boldsymbol{B}$, As in $\boldsymbol{A}$, except that the age of the rat was P11. The interval histogram shows the lack of very long intervals. $\boldsymbol{C}$, As in $\boldsymbol{A}$, except that the age of the rat was P28. Middle, Three complex waveforms; the middle one lacks an eAP. The bottom shows the interval histogram, showing smaller and less variable intervals than at the younger ages. $\boldsymbol{D}$, Surface plot showing the age dependence of the event interval distribution in a total of 142 units. Sixty-three cells from Tritsch et al. (2010) within the P4-P8 range have been included. In each cell, the histogram is normalized to its largest value. Dashed gray line and arrow indicate hearing onset at P13. $E$, Developmental decrease in CV of event intervals. $\boldsymbol{F}$, Developmental increase in average firing rate.

ration of the electrical and release properties of the hair cells (Kros et al., 1998; Beutner and Moser, 2001) and the regression of Kölliker's organ (Tritsch and Bergles, 2010), which drives the action potentials in the hair cells before hearing onset (Tritsch et al., 2007).

\section{Synaptic transmission becomes faster, but not more reliable during development}

Figure $2 A$ shows an overlay of the first complex waveform shown in Figure 1, $A$ and $C$ (middle), illustrating that synaptic transmission in the MNTB became much faster during development. The half-width of the eAP decreased from $0.31 \pm 0.02 \mathrm{~ms}(n=20)$ at $\mathrm{P} 4-\mathrm{P} 6$ to $0.16 \pm 0.015 \mathrm{~ms}(n=12)$ in young-adult rats (Fig. $2 B$ ). The delay between the presynaptic and the postsynaptic spikes also showed a large developmental change, decreasing from $1.83 \pm 0.16 \mathrm{~ms}(n=17)$ at $\mathrm{P} 4-\mathrm{P} 6$ to $0.67 \pm 0.04 \mathrm{~ms}(n=7)$ in young-adult rats (Fig. 2C).

At short intervals between events, the eAP became smaller (Figs. $1 A, 2 D$, inset). In young animals, the amount of depression was much larger at short intervals, and spike depression recovered much more slowly (Fig. 2D). To allow a quantitative comparison of the time course of recovery from spike depression, we fitted a model with a single recovery time constant to the data, as detailed in Materials and Methods. Even though the fit with a single component was not always optimal (Fig. 2 E) (Lorteije et al., 2009), the model could account for as much as $74 \pm 3 \%(n=20)$ of the variance in the AP amplitudes in P4-P6 animals. The use of only a single component also had the advantage that it facilitated a comparison among all cells. In cells from P4-P6 animals, the time constant for recovery from depression was $323 \pm 132 \mathrm{~ms}$ $(n=20)$; on average, spikes depressed by $15 \pm 2 \%$ per AP. After hearing onset, most cells showed little spike depression during spontaneous firing. In cells between P15-P29 in which the fit could account for at least $10 \%$ of the variance in eAP amplitudes, the time constant for recovery was on average only $1.0 \pm 0.1 \mathrm{~ms}$ $(n=4)$. Despite the much slower recovery from spike depression at young ages, the reliability of the synaptic transmission did not change greatly during development; both before and after hearing onset, about half of the cells showed transmission failures during spontaneous activity (Fig. $2 F$ ). Interestingly, before hearing onset almost all failures were observed at interspike intervals $>20 \mathrm{~ms}$.

\section{Developmental changes in short-term plasticity during spontaneous activity in vivo}

The observation that before hearing onset the reliability of the calyx of Held synapse depended on recent history suggested a contribution of STP to synaptic strength. The excellent signal-to-noise ratio of the juxtacellular recordings allowed us to quantify interval-dependent changes in the size of the eEPSP. We previously showed that the size of the eEPSP or the maximum amplitude of its first derivative recorded from the young-adult mouse principal neurons provide a measure for the strength of synaptic transmission (Lorteije et al., 2009); by making simultaneous whole-cell and juxtacellular recordings, we confirmed that this also held true in slice recordings from principal neurons of young (P6-P9) rats $(n=8$, results not shown). Figure $3 A$ illustrates that before hearing onset the mean amplitude of eEPSPs clearly depended on interval. On average, amplitudes were larger both at very short and at very long intervals, creating a U-shaped relation between eEPSP amplitude and $(\log )$ interval (Fig. $3 B$ ). We interpret the increase at short intervals as evidence for synaptic facilitation and the increase at very long intervals as evidence for the presence of recovery from synaptic depression. The failures were only present at the intermediate intervals, when facilitation had decayed, but depression had not yet recovered, illustrating the impact that STP could have on the transmission reliability before hearing onset. To quantify the time course of both types of STP, we fitted the relation between the eEPSP amplitude and its interval after the previous event with a model that took the accumulating effects of both synaptic facilitation and depression and their interaction into account (Varela et al., 1997), as detailed in Materials and Methods. For each re- 
A

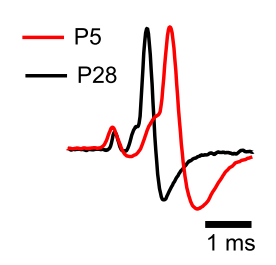

B
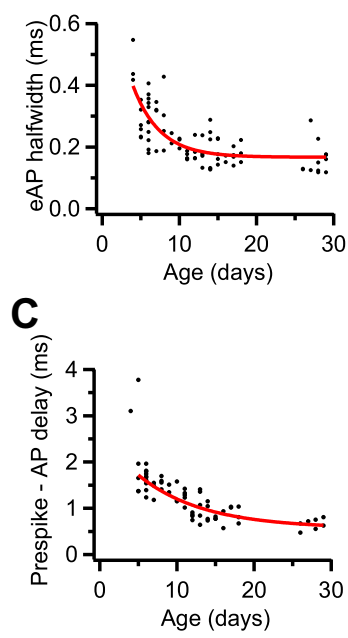

\section{F}
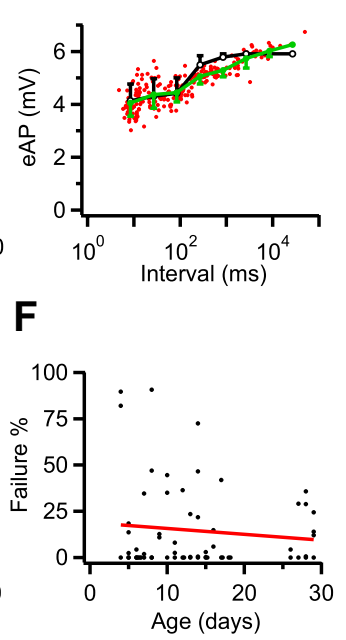

Figure 2. Developmental changes in timing and reliability of synaptic transmission. $\boldsymbol{A}$, The first complex waveform in the middle panels of Figure $1, A$ and $C$, are aligned on the prespike and scaled to the same peak amplitude to illustrate the difference in the time course of the complex waveform at P5 and at P28. B, Developmental changes in eAP half-width. The solid line is an exponential fit with time constant $4 \mathrm{~d}$. C, Developmental changes in latency between prespike and eAP. The solid line is an exponential fit on the data starting at P5, with time constant $8 \mathrm{~d}$. D, Depression of eAP size as a function of eAP interval. eAP sizes from individual recordings ( $n=$ 57) were $\log$ binned and normalized to the average of the 3 bins with the longest intervals before averaging within the different age groups. Inset shows example of depression of eAP size at short intervals in a P5 rat. $\boldsymbol{E}$, Relation between eAP size and log interval. Green trace shows the binned average with SD. Black trace shows model fit with single recovery time constant of 320 ms. $\boldsymbol{F}$, Percentage of subthreshold eEPSPs per cell as a function of age. Red line shows linear regression $(r=-0.1 ; p>0.4)$.

cording, we compared three different configurations: depression alone; facilitation alone; and a combination of synaptic depression and facilitation. To evaluate the goodness-of-fit, we calculated the $r$ value between model and measured values. The $r^{2}$ value provides an estimate of the fraction of the variance in the eEPSP amplitudes that can be explained by the model. A comparison of average measured and fitted eEPSP amplitudes for the model with both facilitation and depression suggests that this model provided an adequate description of the intervaldependent changes in the eEPSP amplitudes (Fig. 3B). For this recording, $70.7 \%$ of the variance could be explained by a combination of synaptic depression and facilitation, whereas this was $62.8 \%$ for a model with only depression. A fit with a model with only facilitation was not possible. To choose between the different models, we evaluated the three fits for each recorded cell, setting a minimum increase of $2.5 \%$ explained variance per component, with each component contributing two extra free parameters. The fit of the data shown in Figure $3 B$ indicated for the facilitation process a $95 \%$ increase per $\mathrm{AP}$, decaying with a time constant of $125 \mathrm{~ms}$, and for the depression a decrease of $37 \%$ per $\mathrm{AP}$, recovering with a time constant of $1.0 \mathrm{~s}$. Shortly before hearing onset, the contribution of STP decreased dramatically. An example of a recording from a P11 rat is shown in Figure 3C. This cell also showed evidence for both facilitation and depression. The amount of facilitation was smaller (62\%), and its decay time course was much faster $(12.7 \mathrm{~ms})$ than in the recording shown in Figure $3 B$. In addition, the amount of depression was much lower, without an obvious change in its recovery time course. The model could account for $32 \%$ of the variance in the eEPSP amplitudes. Figure $3 D$ shows the results of a cell from a young-adult animal (P26). Facilitation again decayed fast (11.5 ms). In this cell, there was no clear contribution of synaptic depression, and the model could account for only $5.2 \%$ of the total variance.

Figure 4 summarizes the dramatic developmental changes in both the kinetics and amount of STP. Between P4 and P8, all recordings showed STP; 18 of 21 cells showed evidence for the presence of both facilitation and depression; in the other three cells, depression dominated. In contrast, at P26-P29 only one cell showed evidence for depression. In 6 of 12 cells, there was evidence for facilitation; in 5 cells, no evidence for either facilitation or depression was observed. Especially around hearing onset, the decay of facilitation became much faster, from values of $123 \pm 14$ $\mathrm{ms}(n=12)$ at $\mathrm{P} 4-\mathrm{P} 6,71 \pm 13 \mathrm{~ms}(n=8)$ at $\mathrm{P} 7-\mathrm{P} 9$, and $12.5 \pm$ $2.3 \mathrm{~ms}(n=11)$ at $\mathrm{P} 13-\mathrm{P} 18$, to a value of only $11.4 \pm 3.0 \mathrm{~ms}(n=$ 6 ) at P26-P29 (Fig. 4A). The time constant for facilitation did not significantly differ between P13-P18 and P26-P29 $(p=0.8)$. The amount of facilitation gradually decreased, from $189 \pm 32 \%$ increase per AP at P4-P6 $(n=12)$ to $23 \pm 4 \%$ at P13-P18 $(n=$ 14 ) and only $12 \pm 6 \%$ at P26-P29 $(n=11)$ (Fig. $4 B)$. The amount of facilitation did not differ significantly between P13P18 and P26-P29 ( $p=0.1)$.

Around the same time, the amount of synaptic depression decreased strongly. In the age range P4-P6, all cells (14/14) showed evidence for depression, whereas this was the case in only 1 of 12 cells at P26-P29. The amount of depression decreased from $38 \pm 4 \%$ per AP at P4-P6 $(n=14)$ to only $3 \pm 1 \%$ at P13-P18 $(n=20)$ (Fig. $4 D)$. In most cells, the recovery from depression was slow, and there were no obvious changes in the time course of the recovery from depression, although the estimates of the recovery time constant were not very reliable as a result of the paucity of very long intervals in most cells after hearing onset (Fig. $4 C$ ). In a few cells, the recovery time constant for synaptic depression was only $\sim 100 \mathrm{~ms}$. In the cells from immature animals, these short time constants appeared to be genuine and not caused by a fit bias owing to a lack of longer intervals. They may be a reflection of the short, Ca-dependent recovery time constants that have been observed in slice recordings (Wang and Kaczmarek, 1998; Sakaba and Neher, 2001).

Figure $4 E$ shows how much of the variance in the eEPSP amplitudes could be accounted for by the model, showing that this contribution decreased from an average of $51 \pm 5 \%$ at P4-P6 $(n=14)$ to only $3 \pm 1 \%$ in the young adults $(\mathrm{P} 26-\mathrm{P} 29 ; n=12)$. In Figure $4 E$, cells without significant facilitation or depression have $0 \%$ explained variance. Even though our criterion for accepting additional components was quite lenient, it is of course hard to exclude that a contribution of STP was somehow missed. However, it is unlikely that this contribution was very large in the young-adult animals, since the explained variance increased on average by only $0.5 \pm 0.1 \%$ if we would have used the fit with both facilitation and depression in each experiment, regardless of the parameter outcome (e.g., negative facilitation). This illustrates that whatever model selection criterion would be chosen, the contribution of STP to the variability in the spontaneous eEPSP amplitudes rapidly becomes quite small after hearing onset. A comparison of Figures $1 H$ and $4 E$ shows that the changes in the firing pattern and the changes in STP happened around the same 
A
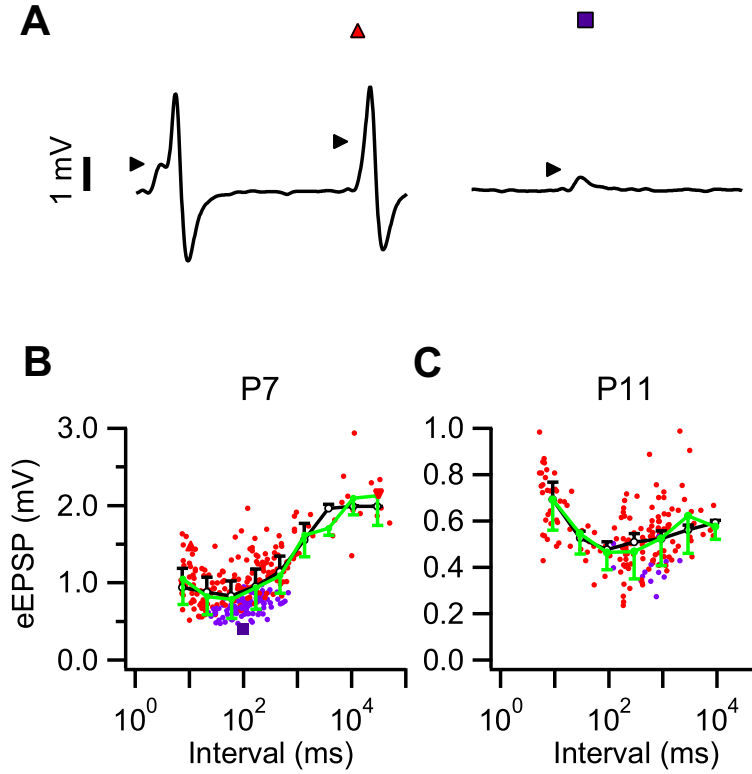

C



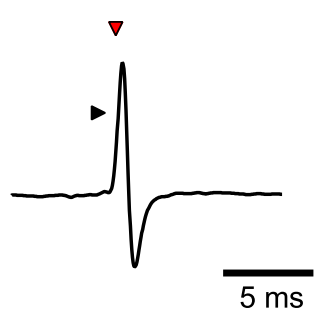

D

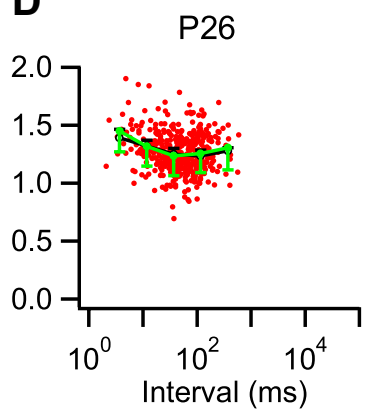

Figure 3. Short-term plasticity changes during development. A, Illustration of complex waveforms from a P7 rat showing synaptic facilitation at short intervals (left), depression at intermediate intervals leading to a postsynaptic failure (middle), and recovery from depression at long intervals (right). Symbols above the waveforms refer to events shown in $\boldsymbol{B}$. $\boldsymbol{B}$, Dependence of eEPSP size on interevent interval. Red dots show individual suprathreshold eEPSP amplitudes, purple dots show subthreshold eEPSP amplitudes, and individual squares, triangles, and inverted triangles refer to examples shown in $\boldsymbol{A}$. Green symbols show binned averages with SD, and black circles indicate the fit with an STP model with both facilitation and depression. Fit parameters were as follows: amplitude $2.0 \mathrm{mV}$; $95 \%$ facilitation per AP, decaying with a time constant of $125 \mathrm{~ms}$; and $38 \%$ depression per AP, decaying with a time constant of $1.0 \mathrm{~s}$. The fit could account for $71 \%$ of the variance in the eEPSP amplitudes. $\boldsymbol{C}$, As in $\boldsymbol{B}$, except the recording was from a $\mathrm{P} 11$ animal. Fit parameters were as follows: amplitude $0.6 \mathrm{mV} ; 62 \%$ facilitation per AP, decaying with a time constant of $12.7 \mathrm{~ms}$; and $2.9 \%$ depression per AP, decaying with a time constant of $4.4 \mathrm{~s}$. The fit could account for $32 \%$ of the variance in the eEPSP amplitudes. $\boldsymbol{D}$, As in $\boldsymbol{B}$, except the recording was from a P26 animal. Fit parameters were as follows: amplitude $1.25 \mathrm{mV}$; 11\% facilitation per AP, decaying with a time constant of $11.5 \mathrm{~ms}$. There was no depression. The fit could account for $5.2 \%$ of the variance in the eEPSP amplitudes.

time. Indeed, the $\mathrm{CV}$ of the event intervals and the amount of variance explained by the STP fit model showed a good correlation $(r=0.81)$, even though individual cells could show synaptic maturation without already having the adult firing pattern. For example, in Figure $3 \mathrm{C}$ a P11 unit is illustrated that showed little depression and a rapid decay of facilitation, yet still had retained the bursting firing pattern (the $\mathrm{CV}$ of its event intervals was 1.8). The large impact of STP on the EPSP variability was also evident from the CV of the eEPSP amplitudes, which decreased from $0.35 \pm 0.02$ at $\mathrm{P} 4-\mathrm{P} 8(n=19)$ to $0.18 \pm 0.01$ at $\mathrm{P} 26-\mathrm{P} 29$ $(n=12)$. The eEPSP amplitude CV was well correlated with the variance explained by the fit model $(r=0.79 ; n=65)$. After subtraction of the variance in the eEPSPs that could be explained by the fit from the total variance, the CV for P4-P8 animals decreased to only $0.16 \pm 0.01$ (i.e., even below the value after hearing onset). As the signal-to-noise ratio was good in each of the recordings that are included in Figure 4, this indicates that stochastic fluctuations in the number of released vesicles are the dominant source for amplitude fluctuations at the rat calyx of Held synapse after hearing, whereas STP is the most important contributor to amplitude fluctuations before hearing onset.

To get an estimate of the impact that short-term facilitation might have on the transmission reliability before hearing onset, we adjusted the measured amplitudes in cells that showed both significant facilitation and failures as if there were no facilitation, as explained in Materials and Methods. In the absence of synaptic facilitation, the estimated percentage of failures increased by $17.9 \pm 3.3 \%$, from a value of $39.9 \pm 11.3 \%$ to $61.4 \pm 9.2 \%(n=$
10). Our data thus suggest that the presence of synaptic facilitation played a substantial role in counteracting the effects of synaptic depression in immature synapses.

\section{Developmental changes in short-term plasticity in slice recordings}

Our finding that the contribution of STP to the variability in spontaneous transmission decreases dramatically just before hearing onset raises the question of whether the observed changes are due to a change in synaptic properties or are a direct consequence of changes in the electrical input pattern, the extracellular milieu, or the postsynaptic voltage-dependent ion channels. To discriminate between these different possibilities, we measured the time course and magnitude of both facilitation and depression in slices from P4-P6 or P13-P16 animals during paired-pulse stimulation. The results obtained in slices were in general agreement with the results obtained during spontaneous activity in vivo. At an extracellular calcium concentration of $1.2 \mathrm{mM}$, which is close to the in vivo concentration (for review, see Borst, 2010), both facilitation and depression of EPSCs were generally observed. An example cell from a P5 rat is shown in Figure 5A. The model fit resulted in a decay time constant of facilitation of $72 \mathrm{~ms}$. It also showed clear depression, of $\sim 25 \%$ per AP, which recovered with a time constant of several seconds. At a calcium concentration of $0.6 \mathrm{~mm}$, the EPSCs were much smaller and synaptic depression was no longer present. Facilitation was still observed, which decayed with an estimated time constant of $47 \mathrm{~ms}$ (Fig. 5B). In contrast, in slices from P13-P16 animals synaptic depression was generally greatly reduced or absent and synaptic facilitation decayed much faster. An example is shown in Figure $5, C$ and $D$. EPSCs were much faster than at P4-P6, in agreement with previous results (Chuhma and Ohmori, 1998; Taschenberger and von Gersdorff, 2000; Joshi and Wang, 2002; Joshi et al., 2004; Koike-Tani et al., 2005). This cell showed both facilitation and depression at a calcium concentration of $1.2 \mathrm{~mm}$ (Fig. $5 C$ ). The facilitation decayed with a time constant of $\sim 7 \mathrm{~ms}$, much faster than in the P5 cell shown in Figure $5 \mathrm{~A}$. This fit also illustrates that the criterion for accepting additional components was lenient, since this recording showed significant depression, even though the amount of depression was quite small. At 0.6 $\mathrm{mm}$, only facilitation was present, which had a similar decay time course as at $1.2 \mathrm{~mm}$ (Fig. 5D).

We also stimulated cells with a protocol with more continuously chosen intervals over a wide range, which was designed to mimic the interval range observed before hearing onset, but lacked the gaps in the interval distribution that were sometimes observed in the in vivo data, as explained in Materials and Methods. A histogram of the interval distribution of this in vivo-like protocol is shown in Figure $6 \mathrm{~A}$. The time derivative of the wholecell current-clamp recording is shown in Figure $6 B$, and at higher time resolution in Figure 6, $C$ and $D$, to illustrate the presence of 


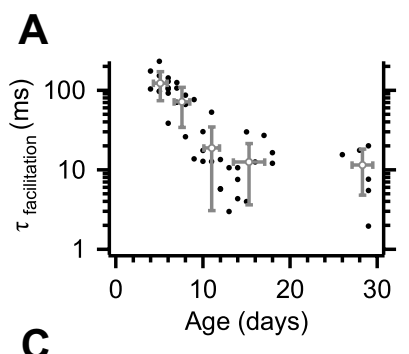

B
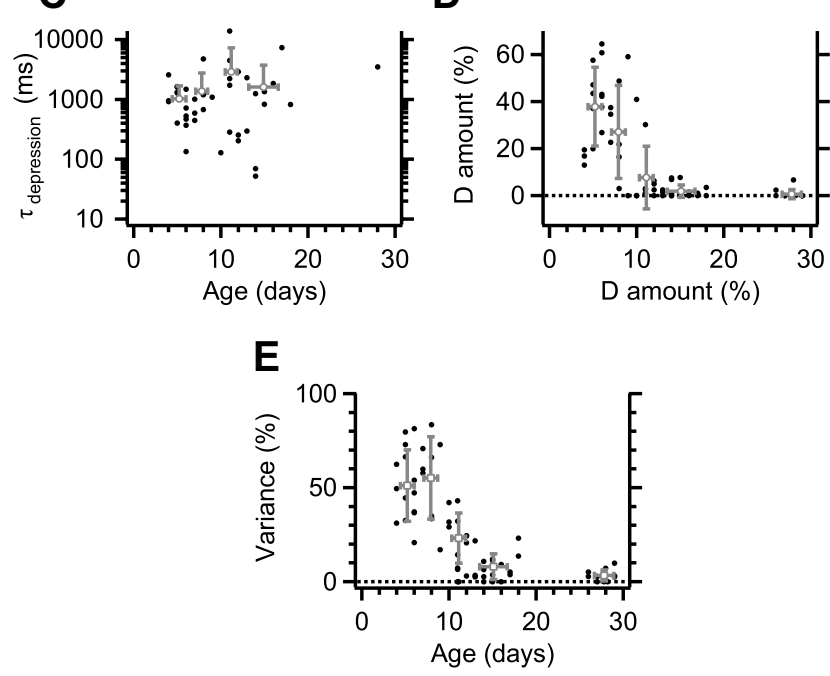

Figure 4. Developmental changes in STP. A, Developmental decrease in the time constant of facilitation, as obtained from the fit with an STP model. Only cells that showed significant facilitation are included ( 45 of 65 cells). Gray symbols show binned averages with SDs. B, As in $A$, showing the developmental changes in the amount of facilitation ( 53 of 65 cells). All cells are included, except when they showed only depression. Cells without significant facilitation are included as $0 \%$. C, Age dependence of the time constant for recovery from depression as obtained from the fit in cells with significant depression (42 of 65 cells). D, Developmental decrease in the amount of depression. Cells without significant depression are included as $0 \%$. , Developmental decrease in the percentage of variance that can be explained by the model fit (coefficient of determination). Cells without both significant facilitation and depression are included as $0 \%$.

short-term facilitation at short intervals and short-term depression at intermediate intervals. This recording is from the same cell as illustrated in Figure 5, $A$ and $B$. The interval dependence of the rate of rise of the intracellularly recorded EPSPs (iEPSPs) at $1.2 \mathrm{~mm}$ calcium is shown in Figure $6 E$, together with the fit with the STP model. The fit indicated a decay time constant for synaptic facilitation of $95 \mathrm{~ms}$ and a clear synaptic depression of $33 \%$ per AP, which recovered slowly. No postsynaptic failures were observed. At a calcium concentration of $0.6 \mathrm{~mm}$, the average rate of rise of EPSPs was strongly reduced, and most EPSPs with a rate of rise $<16 \mathrm{~V} / \mathrm{s}$ failed (Fig. 6 F). Synaptic depression was no longer apparent, but the EPSPs showed facilitation at short intervals, which decayed with a time constant of $\sim 35 \mathrm{~ms}$. Similar results were obtained in voltage-clamp, with both facilitation and depression at $1.2 \mathrm{~mm}$ calcium and only facilitation at $0.6 \mathrm{mM}$ (results not shown).

The same cell from a P15 animal that was illustrated in Figure $5 D-F$ was also probed with the in vivo-like protocol. Both at 1.2 $\mathrm{mm}$ (Fig. 6G) and at $0.6 \mathrm{~mm}$ (Fig. $6 \mathrm{H}$ ), clear facilitation was observed, which decayed with time constants of 9 and $5 \mathrm{~ms}$, respectively. At $1.2 \mathrm{~mm}$, there was also a small depression, similar to Figure $5 C$. No failures were observed at $1.2 \mathrm{~mm}$ calcium, whereas at $0.6 \mathrm{~mm}$ most EPSPs with a rate of rise of $<30 \mathrm{~V} / \mathrm{s}$ were subthreshold. In the in vivo-like current-clamp stimulus protocol,
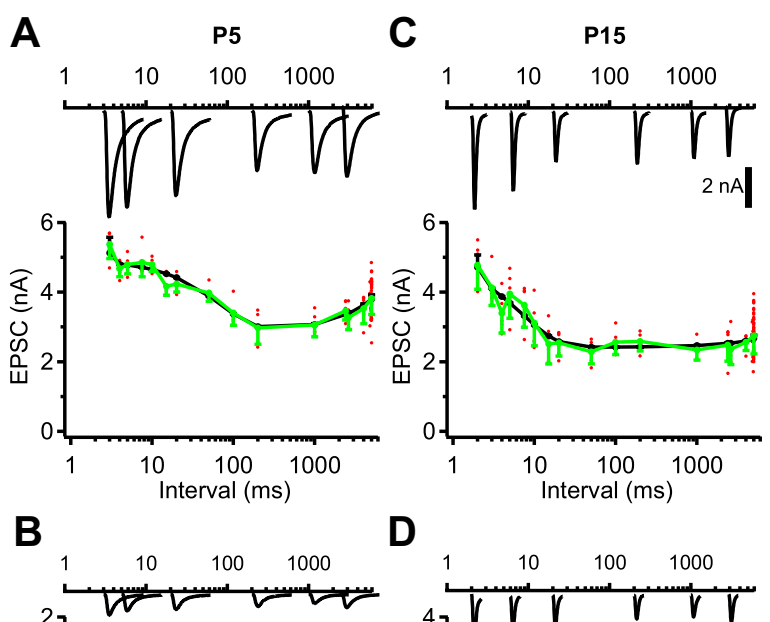

D

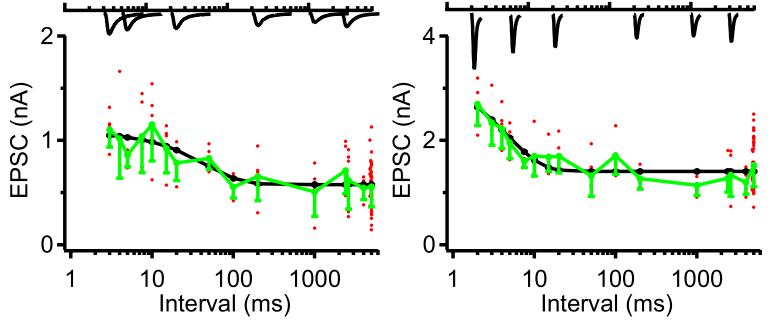

Figure 5. Developmental changes in STP during paired-pulse stimulation in slice recordings. $\boldsymbol{A}$, Top, Example EPSCs obtained at the indicated interval in a P5 whole-cell voltage-clamp experiment at 1.2 mm calcium. Bottom, Red dots show individual EPSC amplitudes, green symbols show binned averages with SD, and black circles show fit with an STP model with both facilitation and depression. Fit parameters were as follows: amplitude $5.2 \mathrm{nA} ; 74 \%$ facilitation per AP, decaying with a time constant of $72 \mathrm{~ms}$; and $25 \%$ depression per AP, decaying with a time constant of $6.5 \mathrm{~s}$. The fit could account for $68 \%$ of the variance in the EPSC amplitudes. $\boldsymbol{B}$, As in $\boldsymbol{A}$, except the calcium concentration was lowered to $0.6 \mathrm{~mm}$. Fit parameters were amplitude $0.6 \mathrm{nA}, 87 \%$ facilitation per AP, decaying with a time constant of $47 \mathrm{~ms}$. The fit could account for $43 \%$ of the variance in the EPSC amplitudes. $\boldsymbol{C}$, As in $\boldsymbol{A}$, except the recording was from a P15 neuron. Fit parameters were as follows: amplitude $3.4 \mathrm{nA} ; 104 \%$ facilitation per AP, decaying with a time constant of $7.3 \mathrm{~ms}$; and $9 \%$ depression per AP, decaying with a time constant of $10.9 \mathrm{~s}$. The fit could account for $57 \%$ of the variance in the EPSC amplitudes. D, As in C, except that calcium concentration was lowered to $0.6 \mathrm{~mm}$. Fit parameters were as follows: amplitude $1.4 \mathrm{nA} ; 136 \%$ facilitation per AP, decaying with a time constant of $4.6 \mathrm{~ms}$. The fit could account for $42 \%$ of the variance in the EPSC amplitudes. The scale bar for EPSCs in $C$ also pertains to EPSCs shown in $\boldsymbol{A}, \boldsymbol{B}$, and $\boldsymbol{D}$.

only two of five P5 and one of four P15 cells showed postsynaptic failures at $1.2 \mathrm{~mm}$; at $0.6 \mathrm{~mm}$, four of four P5 and three of four P15 cells showed failures. Failures were generally not observed at short intervals, which is in agreement with the results obtained in vivo. The estimated threshold EPSP amplitude, the amplitude at which about half of the EPSPs did not induce an AP, ranged between 16 and $30 \mathrm{~V} / \mathrm{s}$ at P5 $(n=4)$, and between 30 and $35 \mathrm{~V} / \mathrm{s}$ at $\mathrm{P} 15(n=3)$.

Our in vitro data thus confirm the observations made in vivo that facilitation becomes faster and depression is reduced during development. There was some variability in the estimates for the decay of facilitation, ranging for the six different protocols from $21 \mathrm{~ms}$ for the in vivo-like stimulation under voltage-clamp at 1.2 $\mathrm{mm}$ to $95 \mathrm{~ms}$ for the same stimulus under current-clamp for the P5 cell, and between $5 \mathrm{~ms}$ for the paired-pulse protocol at $1.2 \mathrm{~mm}$ and $14 \mathrm{~ms}$ for the in vivo-like protocol under voltage-clamp at 0.6 $\mathrm{mm}$ for the P15 cell. However, there were no systematic differences in the amount or decay time constant of facilitation or of depression obtained with the different protocols across different cells. The lack of systematic differences between these parameters between voltage-clamp and current-clamp recordings and between paired-pulse and more random stimulation indicates that 
A



E

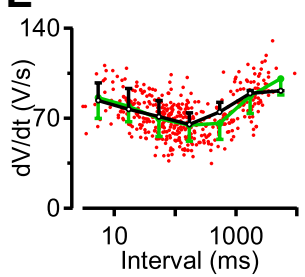

$\mathbf{F}$

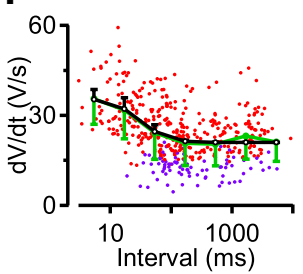

D
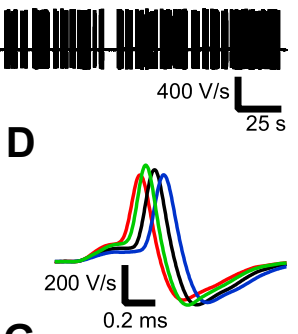

G

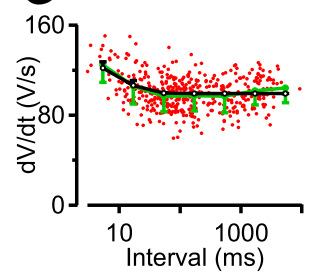

$\mathbf{H}$

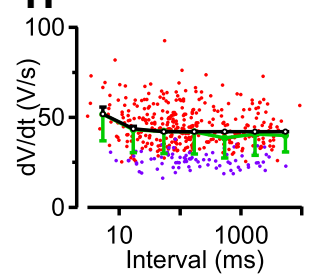

Figure 6. Developmental changes in STP in slices during in vivo-like stimulation. $\boldsymbol{A}$, Histogram of intervals for stimulus protocol. $\boldsymbol{B}$, Time derivative of whole-cell current-clamp responses of a P5 cell to in vivo-like stimulus protocol. Note the large range and random character of intervals between stimuli. $\boldsymbol{C}$, Small segment of the responses shown in $\boldsymbol{B}$. $\boldsymbol{D}$, Responses shown in Caligned at the rising phase of the iEPSP. Colors correspond to markers above the trace in $\boldsymbol{C}$. , Interval dependence of the iEPSP maximal amplitude in a P5 cell at $1.2 \mathrm{~mm}$ calcium. The green curve indicates binned average. Error bars show the SD. The black circles are the result of the fit with an STP model, with amplitude $91.4 \mathrm{~V} / \mathrm{s} ; 74 \%$ facilitation per AP, decaying with a time constant of $95 \mathrm{~ms}$; and $33 \%$ depression per AP, decaying with a time constant of $0.5 \mathrm{~s}$. The fit could account for $50 \%$ of the variance in the iEPSP amplitudes. $\boldsymbol{F}$, As in $\boldsymbol{E}$, except that the calcium concentration was $0.6 \mathrm{~mm}$. Red circles are suprathreshold EPSPs, blue subthreshold. The fit parameters were as follows: amplitude $21 \mathrm{~V} / \mathrm{s}, 70 \%$ facilitation per AP, decaying with a time constant of $35 \mathrm{~ms}$. The fit accounted for $28 \%$ of the amplitude variance. $\boldsymbol{G}$, As in $\boldsymbol{E}$, except that the recording was from a P15 animal. Fit parameters were as follows: amplitude $103 \mathrm{~V} / \mathrm{s} ; 47 \%$ facilitation per AP, decaying with a time constant of $10.2 \mathrm{~ms} ; 1 \%$ depression per AP, decaying with a time constant of $1.7 \mathrm{~s}$. The fit accounted for $18 \%$ of the amplitude variance. $\boldsymbol{H}$, As in $\mathbf{G}$, except that the calcium concentration was $0.6 \mathrm{~mm}$. Fit parameters were as follows: amplitude 42 $\mathrm{V} / \mathrm{s}, 74 \%$ facilitation per AP, decaying with a time constant of $5.4 \mathrm{~ms}$. Fit accounted for $4 \%$ of the variance.

the results obtained in vivo can be used as a quantitative measure for the kinetics and amount of STP at the calyx of Held synapse. We therefore averaged the different significant estimates for these parameters to obtain a single estimate per cell. Facilitation became much faster after hearing onset, with the decay accelerating from $31.6 \pm 7.7 \mathrm{~ms}(n=5$; range, $6-50 \mathrm{~ms})$ at $\mathrm{P} 4-\mathrm{P} 6$ to $6.6 \pm 0.8$ $\mathrm{ms}(n=5$; range, $5-9 \mathrm{~ms} ; p=0.03)$ at $\mathrm{P} 13-\mathrm{P} 16$; in addition, the amount of facilitation became smaller $(122 \pm 30 \%$ vs $51 \pm 13 \%$; $p=0.08$ ). The amount of depression in the presence of $1.2 \mathrm{~mm}$ calcium decreased from $27.6 \pm 3.8 \%(n=5)$ at P4-P6 to only $1.9 \pm 0.8 \%(n=5 ; p=0.002)$ at P13-P16, but there was no change in the time constant of the recovery from depression $(1.9 \pm 0.2$ vs $1.9 \pm 1.0 \mathrm{~s} ; p>0.9)$. At $0.6 \mathrm{~mm}$, three of five cells at $\mathrm{P} 5$ and none of the five cells at P15 showed significant depression. The percentage of the variance in the synaptic potentials or currents during the in vivo-like stimulation at $1.2 \mathrm{~mm}$ that could be ascribed to STP decreased strongly after hearing onset. On aver-

age, this percentage decreased from $62 \pm 6 \%$ at P 5 to only $8 \pm 3 \%$ at $\mathrm{P} 15(n=5)$.

The comparison between the in vivo spontaneous data and the data obtained in slice recordings shows that despite the large experimental differences between the two approaches, the main developmental changes were consistent. This indicates that these changes were not predominantly the result of changes in firing pattern, postsynaptic voltage-dependent ion channels, or the composition of the extracellular environment, even though a contribution of each of these factors cannot be excluded. A difference between both types of experiments was that the time constant for the decay of facilitation was lower in the in vivo spontaneous data than in the age-matched slice experiments. The cause for this difference is largely unknown. It is unlikely to be due to a cooling of the exposed brain surface in the in vivo experiments, since the delay between the presynaptic and postsynaptic action potential was not significantly different $(p=0.09)$ in P5-P6 animals under both conditions, and in addition the decay of facilitation changes little between 33 and $38^{\circ} \mathrm{C}$ (Klyachko and Stevens, 2006). A difference between extracellular and intracellular measurements may contribute, since the eEPSP amplitude becomes difficult to measure accurately when it becomes relatively large (Fig. 3A) (Lorteije et al., 2009). Facilitation can therefore lead to an underestimation at short intervals, and thus to an apparently larger decay of facilitation. An analysis of simultaneous intracellular and extracellular recordings showed that extracellularly measured time constants for the decay of facilitation can be somewhat larger (results not shown), but this effect is limited in its impact. Decay time constants in vivo were similar when, instead of the amplitude, we used the peak of the first time derivative of the eEPSP (results not shown), a measure that is less sensitive to ceiling effects, but more sensitive to confounding effects of the prespike (Lorteije et al., 2009). Also, the magnitude of the facilitation was similar in vivo and in vitro, arguing against a large underestimation during the in vivo experiments. Finally, the difference between in vivo and in vitro is unlikely to be due to an interaction with depression, since the amount and time course of facilitation were similar at low and at physiological release probabilities in our slice experiments, in agreement with a recent report showing that the decay of facilitation is similar in the presence of depression (Müller et al., 2010).

\section{Developmental changes in short-term plasticity during electrical stimulation in vivo}

In the in vivo experiments, the firing pattern before and after hearing onset differed greatly, whereas in the slice experiments both age groups received the same stimulation protocols. In the in vivo situation, long pauses become rare after P11; because of the slow recovery from synaptic depression, the spontaneous activity may therefore tonically depress a synapse (Boudreau and Ferster, 2005; Reig et al., 2006; Hermann et al., 2007; Hermann et al., 2009). To further delineate the differences in STP before and after hearing onset under conditions that approximated the physiological situation as closely as possible, we therefore applied the stimulation protocols used for the slice experiments during in vivo recordings. In these experiments, spontaneous activity was completely abolished by ablation of the contralateral cochlea and afferent activity was evoked by placement of a bipolar electrode at the midline, as detailed in Materials and Methods. A limitation of these experiments was that the field potentials could be large because many cells were activated almost simultaneously. If time permitted, both the paired-pulse protocol and the in vivo-like stimulation protocol were tested. We compared the impact of 
A

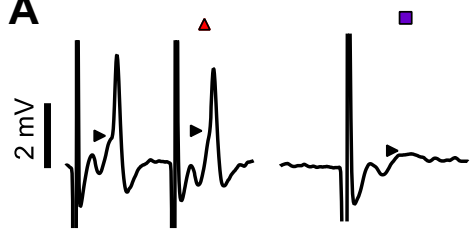

B



C $\quad{ }^{2 m} 28$



Figure 7. Developmental in vivo changes in STP during electrical stimulation following cochlear ablation. A, Illustration of electrically evoked complex waveforms from a P6 rat showing synaptic facilitation at short intervals (left), depression at intermediate intervals leading to a postsynaptic failure (middle), and recovery from depression at long intervals (right) animal. Symbols above the waveforms refer to events shown in $\boldsymbol{B}$. $\boldsymbol{B}$, Dependence of eEPSP size on stimulus interval. Same in vivo-like protocol was used as in Figure 6. Red dots show individual suprathreshold eEPSP amplitudes, purple dots show subthreshold eEPSP amplitudes, and individual squares, triangles, and inverted triangles refer to examples shown in $\boldsymbol{A}$. Green symbols show binned averages with SD, and black circles indicate fit with an STP model with both facilitation and depression. Fit parameters were as follows: amplitude $0.5 \mathrm{mV} ; 130 \%$ facilitation per AP, decaying with a time constant of $97 \mathrm{~ms}$; and $29 \%$ depression per AP, decaying with a time constant of $725 \mathrm{~ms}$. The fit could account for $50 \%$ of the variance in the eEPSP amplitudes. $\boldsymbol{C}$, As in $\boldsymbol{B}$, except that the recording was from a P28 animal. Fit parameters were as follows: amplitude $0.8 \mathrm{mV} ; 64 \%$ facilitation per AP, decaying with a time constant of $6.8 \mathrm{~ms}$; there was no depression. The fit could account for $15 \%$ of the variance in the eEPSP amplitudes.

STP at P5-P6 and at P26-P28. Figure 7A shows examples of electrically evoked eEPSPs at different intervals in a P6 animal. As was also the case for the spontaneous data, before hearing onset the mean eEPSP clearly depended on the interval (Fig. $7 B$ ). In young-adult animals, the contribution of STP was much smaller (Fig. 7C). In the young animals, all three cells displayed evidence for depression, and in two of three cells there was also facilitation. In the young-adult animals, one of five cells did not show evidence for STP; in the other four cells, facilitation alone, depression, or a combination (one cell) was observed. During development, the time constant of facilitation decreased from $69 \pm 20 \mathrm{~ms}$ at P5-P6 $(n=3)$ to $5.5 \pm 1.0 \mathrm{~ms}$ at P26-P28 $(n=3)$ (Fig. $8 A$ ). The amount of facilitation decreased from $96 \pm 56 \%$ $(n=3)$ at P5-P6 to $52 \pm 21 \%(n=4)$ in the young-adult animals (Fig. $8 \mathrm{~B}$ ). At the same time, the amount of depression per AP decreased from $22 \pm 8 \%(n=4)$ to only $4 \pm 2 \%(n=6)$ (Fig. $8 C$ ), whereas there were no clear changes in the time constant for recovery from depression $(1.4 \pm 0.5$ vs $1.5 \pm 0.4 \mathrm{~s}$ ) (Fig. $8 D$ ). The percentage of variance explained by the best model during the in vivo-like stimulation decreased from $50 \pm 6 \%(n=3)$ to $9 \pm 2 \%$ $(n=6)$ (Fig. $8 E$ ). Despite the limited number of experiments and the more problematic analysis caused by the presence of field potentials, we conclude that the general developmental changes observed both for the spontaneous in vivo and the slice experiments were also observed during electrical stimulation in the silenced in vivo situation.

\section{Discussion}

We studied the developmental changes in STP at the rat calyx of Held synapse during in vivo recordings. We found clear evidence
A


B

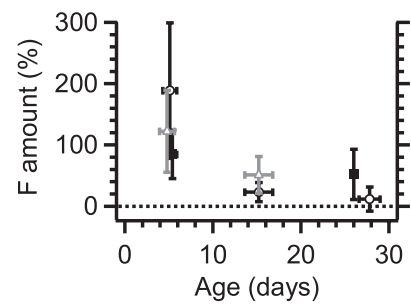

D
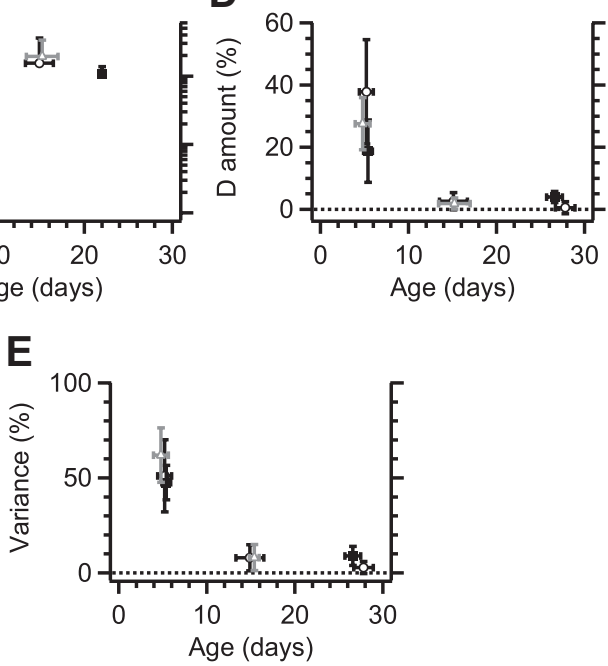

Figure 8. Comparison of developmental changes in STP in vivo and in vitro. The following three types of experiments are included: spontaneous in vivo data (Fig. 4, open circles; same data), slice data (open gray triangle), and electrically evoked in vivo data (closed squares). Symbols show binned averages with SDs. If multiple protocols from the same cell were applicable, the average from the different protocols was used. $A$, Developmental decrease in time constant of facilitation, as obtained from the fit with an STP model. Only fits that showed significant facilitation are included. $\boldsymbol{B}$, As in $\boldsymbol{A}$, showing the developmental changes in the amount of facilitation. Fits showing only depression are not included. $C$, Age dependence of the time constant for recovery from depression as obtained from the fit in cells with significant depression. Fits for slice experiments performed at $0.6 \mathrm{~mm}$ were not included to calculate the amount or time constant of depression. $D$, Developmental decrease in the amount of depression. Fits without significant depression were included as $0 \%$. E, Developmental decrease in the coefficient of determination, the percentage of variance that can be explained by the model fit. For stimulation experiments, only the in vivo-like protocols were included. Slice experiments performed at $0.6 \mathrm{~mm}$ were not included. Fits without both significant facilitation and depression were included as $0 \%$.

for the presence of STP in immature synapses, whereas just before hearing onset the impact of STP greatly decreased or even disappeared. Control experiments, both in slices and in vivo, suggested that these differences mostly resulted from presynaptic changes, and not from changes in firing pattern, postsynaptic voltagedependent ion channels, or the composition of the extracellular environment. The observed dramatic changes in STP just before hearing onset are likely to play an essential role in the conversion of the calyx of Held synapse into an auditory relay synapse.

\section{Developmental changes in transmission speed}

We observed a gradual increase in speed during postnatal development, with relatively little change after hearing onset. Based on experiments performed in slices, multiple factors contributed to these changes, including faster presynaptic and postsynaptic action potentials and faster EPSCs (Wu and Oertel, 1987; Chuhma and Ohmori, 1998; Taschenberger and von Gersdorff, 2000; Futai et al., 2001; Joshi and Wang, 2002; Joshi et al., 2004; Koike-Tani et al., 2005; Kushmerick et al., 2006). The faster action potentials are 
presumably due to an increased density of Kv3 potassium and other voltage-dependent ion channels (for review, see Johnston et al., 2010).

One other important developmental change was that the principal neurons became much more resistant to spike depression. Voltage-clamp measurements from principal neurons in slices have shown a biphasic recovery of sodium currents with a fast recovery time constant of $\sim 1 \mathrm{~ms}$ and a slow time constant of $\sim 100 \mathrm{~ms}$ at room temperature (Leão et al., 2005); during development, the contribution of the slow time constant decreases. The fast time constant of recovery observed previously in slices was much smaller than the minimum interevent interval that we generally observed in our in vivo experiments before hearing onset, whereas the very slow recovery that we did observe was even slower than the slow time constant measured previously in slices. After hearing onset, when minimum intervals generally became much shorter, we did observe the fast recovery component, whereas the slow recovery component was strongly reduced or even absent, in agreement with the results obtained previously in slices (Leão et al., 2005). The much greater resistance to spike depression is likely to play an essential role in the transformation of the calyx of Held synapse into a fast relay.

\section{Short-term plasticity before hearing onset}

We found a large contribution of both short-term facilitation and short-term depression in the immature calyx of Held synapse. Facilitation was not observed in each cell, probably because it can only be uncovered when release probability is not very high (Borst et al., 1995). The estimated amount and time course of facilitation and depression generally matched previous slice estimates (von Gersdorff et al., 1997; Felmy et al., 2003; Kushmerick et al., 2006; Müller et al., 2007, 2008) and the estimates we obtained both in slices and during in vivo stimulation, except that the decay of facilitation in the immature synapse was somewhat slower in vivo.

\section{Mechanisms underlying the developmental decrease in short-term depression}

The synaptic depression was most likely predominantly presynaptic, since postsynaptic receptor desensitization or saturation is typically observed only during longer lasting trains at high frequencies (Neher and Sakaba, 2001; Taschenberger et al., 2002; Wong et al., 2003), and recovery from postsynaptic receptor desensitization is faster than the recovery from synaptic depression observed here (Joshi et al., 2004; Taschenberger et al., 2005). The depression is probably caused by depletion of the readily releasable pool of vesicles (Schneggenburger et al., 1999; Wu and Borst, 1999) with an additional contribution of presynaptic calcium channel inactivation (Forsythe et al., 1998; Xu and $\mathrm{Wu}, 2005$ ).

Just before hearing onset, the contribution of STP changed dramatically. The timing of these changes did not indicate a major role for sensory-evoked activity, in agreement with the idea that many aspects of synaptic maturation at the calyx of Held synapse are relatively hard wired (Erazo-Fischer et al., 2007). The amount of depression decreased strongly without an apparent change in its recovery time course, even though the paucity of long intervals made it hard to estimate this. The most likely explanation for this decrease is a strong decrease in the amount of vesicle depletion. Possible causes include differences in the organization of the release sites, an increase in vesicle pool size, the number of docked vesicles, the number of active zones, exocytotic efficiency (amount of exocytosis per Ca influx), or Ca current facilitation, and a decrease in the release probability
(Taschenberger and von Gersdorff, 2000; Iwasaki and Takahashi, 2001; Taschenberger et al., 2002; Kushmerick et al., 2006; Wimmer et al., 2006; Yang et al., 2010). Since quantal analysis suggested release probability to be low in the young-adult calyx of Held (Lorteije et al., 2009), it seems likely that the developmental reduction of release probability made a large contribution to the decreased impact of short-term depression. A developmental reduction of release probability has also been observed at other synapses, for example in cortex (for review, see Feldmeyer and Radnikow, 2009).

\section{The importance of synaptic facilitation during burst firing in developing synapses}

Before hearing onset, the synaptic facilitation played an important role in counteracting the large synaptic depression. The observed characteristic burst pattern, with multiple microbursts interspersed by very long intervals (Tritsch et al., 2010), is thus an efficient way of relaying information from the periphery to central synapses. Similar firing patterns have been observed in the developing mouse MNTB (Sonntag et al., 2009), and more peripherally in the auditory system (Brugge and O'Connor, 1984; Walsh and McGee, 1987) and in other developing sensory systems (Blankenship and Feller, 2010), suggesting that synaptic facilitation may have a similar function in these developing synapses. The strong developmental reduction in synaptic depression made the opposing effect of facilitation less opportune, and, indeed, we saw a decrease in the amount of facilitation and a much faster decay. As a result, the impact of synaptic facilitation decreased strongly around the same time that the bursting pattern disappeared. A very rapid decay of synaptic facilitation has previously been observed in the endbulb synapse of the cochlear bushy cells and at the cerebellar mossy fiber-granule cell synapse, both of which are also specialized in high-frequency signaling (Saviane and Silver, 2006; Kuenzel et al., 2011).

\section{Mechanisms underlying the developmental acceleration of the decay of facilitation}

Synaptic facilitation in the calyx of Held depends on the buildup of residual calcium (Felmy et al., 2003; Müller et al., 2007, 2008). The most likely explanation for the strong increase in the decay speed after the onset of hearing is therefore that the $\mathrm{Ca}^{2+}$ concentration in the terminal decays much more rapidly in mature animals. After a presynaptic action potential, $\mathrm{Ca}^{2+}$ can bind to calcium buffers or be cleared by pumps (for review, see Neher and Sakaba, 2008). Evidence for a developmental increase in both $\mathrm{Ca}^{2+}$ binding capacity and clearance rates has been obtained at the calyx of Held synapse (Chuhma et al., 2001). Whereas the immature calyx has a relatively small calcium buffer capacity (Helmchen et al., 1997), the calyx expresses, among others, the calcium-binding proteins calretinin and parvalbumin, whose expression increases during development (Lohmann and Friauf, 1996; Felmy and Schneggenburger, 2004). The slow calciumbinding protein parvalbumin has been shown to speed up the decay of short-term facilitation at the calyx of Held synapse (Müller et al., 2007), suggesting that a developmental increase in its concentration may contribute to the observed changes in facilitation. $\mathrm{Ca}^{2+}$ is extruded from the calyx by a combination of several pumps (Kim et al., 2005), whose density may increase during development. Morphological changes may also contribute to faster clearance. Around hearing onset, the calyx starts to assume its mature, floral-like structure (Kandler and Friauf, 1993; Kil et al., 1995; Ford et al., 2009). By increasing the surface- 
to-volume ratio, the more fenestrated, open structure may speed up presynaptic calcium clearance.

\section{Replenishment of the readily releasable pool in the adult calyx}

In slice recordings, the recovery from synaptic depression can be biphasic, with the slow time constant matching the recovery observed here in most synapses. The fast time constant is thought to reflect both a calcium-dependent increase in vesicle replenishment and an increase in release probability of "reluctant," rapidly replenishing vesicles (Wang and Kaczmarek, 1998; Wu and Borst, 1999; Sakaba and Neher, 2001; Hosoi et al., 2007; Müller et al., 2010). As this rapid recovery phase was not observed in most of the present experiments, the most parsimonious explanation is that the demands on the synapse apparently were not sufficient to prolong the $\mathrm{Ca}^{2+}$ decay time course appreciably. Even though we cannot exclude that this rapid phase may become apparent during acoustic stimulation, this was not the case in the mouse calyx of Held synapse or the related gerbil endbulb of Held synapse (Lorteije et al., 2009; Kuenzel et al., 2011). This rapid decay can be expected to considerably limit the time window during which Ca-dependent processes can affect the size or the release probability of the readily releasable pool. We speculate that the combination of limited depletion owing to low release probability and a short window of increased replenishment immediately following a presynaptic action potential are sufficient to allow the adult calyx to maintain its output even at high frequencies. The timing of these changes suggests that the calyx of Held synapse is ready to assume its relay function when hearing starts.

\section{References}

Beutner D, Moser T (2001) The presynaptic function of mouse cochlear inner hair cells during development of hearing. J Neurosci 21:4593-4599.

Blankenship AG, Feller MB (2010) Mechanisms underlying spontaneous patterned activity in developing neural circuits. Nat Rev Neurosci $11: 18-29$.

Blatchley BJ, Cooper WA, Coleman JR (1987) Development of auditory brainstem response to tone pip stimuli in the rat. Brain Res 429:75-84.

Borst JG (2010) The low synaptic release probability in vivo. Trends Neurosci 33:259-266.

Borst JG, Helmchen F, Sakmann B (1995) Pre- and postsynaptic whole-cell recordings in the medial nucleus of the trapezoid body of the rat. J Physiol 489:825-840.

Boudreau CE, Ferster D (2005) Short-term depression in thalamocortical synapses of cat primary visual cortex. J Neurosci 25:7179-7190.

Brugge JF, O'Connor TA (1984) Postnatal functional development of the dorsal and posteroventral cochlear nuclei of the cat. J Acoust Soc Am 75:1548-1562.

Chuhma N, Ohmori H (1998) Postnatal development of phase-locked high-fidelity synaptic transmission in the medial nucleus of the trapezoid body of the rat. J Neurosci 18:512-520.

Chuhma N, Koyano K, Ohmori H (2001) Synchronisation of neurotransmitter release during postnatal development in a calyceal presynaptic terminal of rat. J Physiol 530:93-104.

Erazo-Fischer E, Striessnig J, Taschenberger H (2007) The role of physiological afferent nerve activity during in vivo maturation of the calyx of Held synapse. J Neurosci 27:1725-1737.

Feldmeyer D, Radnikow G (2009) Developmental alterations in the functional properties of excitatory neocortical synapses. J Physiol 587:1889-1896.

Felmy F, Schneggenburger R (2004) Developmental expression of the $\mathrm{Ca}^{2+}$-binding proteins calretinin and parvalbumin at the calyx of Held of rats and mice. Eur J Neurosci 20:1473-1482.

Felmy F, Neher E, Schneggenburger R (2003) Probing the intracellular calcium sensitivity of transmitter release during synaptic facilitation. Neuron 37:801-811.

Ford MC, Grothe B, Klug A (2009) Fenestration of the calyx of Held occurs sequentially along the tonotopic axis, is influenced by afferent activity, and facilitates glutamate clearance. J Comp Neurol 514:92-106.

Forsythe ID (1994) Direct patch recording from identified presynaptic terminals mediating glutamatergic EPSCs in the rat CNS, in vitro. J Physiol 479:381-387.

Forsythe ID, Tsujimoto T, Barnes-Davies M, Cuttle MF, Takahashi T (1998) Inactivation of presynaptic calcium current contributes to synaptic depression at a fast central synapse. Neuron 20:797-807.

Futai K, Okada M, Matsuyama K, Takahashi T (2001) High-fidelity transmission acquired via a developmental decrease in NMDA receptor expression at an auditory synapse. J Neurosci 21:3342-3349.

Geal-Dor M, Freeman S, Li G, Sohmer H (1993) Development of hearing in neonatal rats: air and bone conducted ABR thresholds. Hear Res 69:236-242.

Guinan JJ Jr, Li RY (1990) Signal processing in brainstem auditory neurons which receive giant endings (calyces of Held) in the medial nucleus of the trapezoid body of the cat. Hear Res 49:321-334.

Habets RL, Borst JG (2007) Dynamics of the readily releasable pool during post-tetanic potentiation in the rat calyx of Held synapse. J Physiol 581:467-478.

Heil P, Neubauer H, Irvine DR, Brown M (2007) Spontaneous activity of auditory-nerve fibers: insights into stochastic processes at ribbon synapses. J Neurosci 27:8457-8474.

Helmchen F, Borst JG, Sakmann B (1997) Calcium dynamics associated with a single action potential in a CNS presynaptic terminal. Biophys J 72:1458-1471.

Hermann J, Pecka M, von Gersdorff H, Grothe B, Klug A (2007) Synaptic transmission at the calyx of Held under in vivo-like activity levels. J Neurophysiol 98:807-820.

Hermann J, Grothe B, Klug A (2009) Modeling short-term synaptic plasticity at the calyx of Held using in vivo-like stimulation patterns. J Neurophysiol 101:20-30.

Horvitz DG, Thompson DJ (1952) A generalization of sampling without replacement from a finite universe. J Am Stat Assoc 47:663-685.

Hosoi N, Sakaba T, Neher E (2007) Quantitative analysis of calciumdependent vesicle recruitment and its functional role at the calyx of Held synapse. J Neurosci 27:14286-14298.

Iwasaki S, Takahashi T (2001) Developmental regulation of transmitter release at the calyx of Held in rat auditory brainstem. J Physiol 534:861-871.

Jewett DL, Romano MN (1972) Neonatal development of auditory system potentials averaged from the scalp of rat and cat. Brain Res 36:101-115.

Johnston J, Forsythe ID, Kopp-Scheinpflug C (2010) Going native: voltagegated potassium channels controlling neuronal excitability. J Physiol 588:3187-3200.

Joshi I, Wang LY (2002) Developmental profiles of glutamate receptors and synaptic transmission at a single synapse in the mouse auditory brainstem. J Physiol 540:861-873.

Joshi I, Shokralla S, Titis P, Wang LY (2004) The role of AMPA receptor gating in the development of high-fidelity neurotransmission at the calyx of Held synapse. J Neurosci 24:183-196.

Kandler K, Friauf E (1993) Pre- and postnatal development of efferent connections of the cochlear nucleus in the rat. J Comp Neurol 328:161-184.

Kil J, Kageyama GH, Semple MN, Kitzes LM (1995) Development of ventral cochlear nucleus projections to the superior olivary complex in gerbil. J Comp Neurol 353:317-340.

Kim MH, Korogod N, Schneggenburger R, Ho WK, Lee SH (2005) Interplay between $\mathrm{Na}^{+} / \mathrm{Ca}^{2+}$ exchangers and mitochondria in $\mathrm{Ca}^{2+}$ clearance at the calyx of Held. J Neurosci 25:6057-6065.

Klyachko VA, Stevens CF (2006) Temperature-dependent shift of balance among the components of short-term plasticity in hippocampal synapses. J Neurosci 26:6945-6957.

Koike-Tani M, Saitoh N, Takahashi T (2005) Mechanisms underlying developmental speeding in AMPA-EPSC decay time at the calyx of Held. J Neurosci 25:199-207.

Kopp-Scheinpflug C, Tolnai S, Malmierca MS, Rübsamen R (2008) The medial nucleus of the trapezoid body: comparative physiology. Neuroscience 154:160-170.

Kros CJ, Ruppersberg JP, Rüsch A (1998) Expression of a potassium current in inner hair cells during development of hearing in mice. Nature 394:281-284.

Kuenzel T, Borst JG, van der Heijden M (2011) Factors controlling the 
input-output relationship of spherical bushy cells in the gerbil cochlear nucleus. J Neurosci 31:4260-4273.

Kushmerick C, Renden R, von Gersdorff H (2006) Physiological temperatures reduce the rate of vesicle pool depletion and short-term depression via an acceleration of vesicle recruitment. J Neurosci 26:1366-1377.

Leão RM, Kushmerick C, Pinaud R, Renden R, Li GL, Taschenberger H, Spirou G, Levinson SR, von Gersdorff H (2005) Presynaptic $\mathrm{Na}^{+}$channels: locus, development, and recovery from inactivation at a high-fidelity synapse. J Neurosci 25:3724-3738.

Lohmann C, Friauf E (1996) Distribution of the calcium-binding proteins parvalbumin and calretinin in the auditory brainstem of adult and developing rats. J Comp Neurol 367:90-109.

Lorteije JA, Borst JG (2011) Contribution of the mouse calyx of Held synapse to tone adaptation. Eur J Neurosci 33:251-258.

Lorteije JA, Rusu SI, Kushmerick C, Borst JG (2009) Reliability and precision of the mouse calyx of Held synapse. J Neurosci 29:13770-13784.

Mc Laughlin M, van der Heijden M, Joris PX (2008) How secure is in vivo synaptic transmission at the calyx of Held? J Neurosci 28:10206-10219.

Müller M, Felmy F, Schwaller B, Schneggenburger R (2007) Parvalbumin is a mobile presynaptic $\mathrm{Ca}^{2+}$ buffer in the calyx of Held that accelerates the decay of $\mathrm{Ca}^{2+}$ and short-term facilitation. J Neurosci 27:2261-2271.

Müller M, Felmy F, Schneggenburger R (2008) A limited contribution of $\mathrm{Ca}^{2+}$ current facilitation to paired-pulse facilitation of transmitter release at the rat calyx of Held. J Physiol 586:5503-5520.

Müller M, Goutman JD, Kochubey O, Schneggenburger R (2010) Interaction between facilitation and depression at a large CNS synapse reveals mechanisms of short-term plasticity. J Neurosci 30:2007-2016.

Neher E, Sakaba T (2001) Combining deconvolution and noise analysis for the estimation of transmitter release rates at the calyx of Held. J Neurosci 21:444-461.

Neher E, Sakaba T (2008) Multiple roles of calcium ions in the regulation of neurotransmitter release. Neuron 59:861-872.

Reig R, Gallego R, Nowak LG, Sanchez-Vives MV (2006) Impact of cortical network activity on short-term synaptic depression. Cereb Cortex 16:688-695.

Rodríguez-Contreras A, van Hoeve JS, Habets RL, Locher H, Borst JG (2008) Dynamic development of the calyx of Held synapse. Proc Natl Acad Sci U S A 105:5603-5608.

Rybak LP, Whitworth C, Scott V (1992) Development of endocochlear potential and compound action potential in the rat. Hear Res 59:189-194.

Sakaba T, Neher E (2001) Calmodulin mediates rapid recruitment of fastreleasing synaptic vesicles at a calyx-type synapse. Neuron 32:1119-1131.

Saviane C, Silver RA (2006) Fast vesicle reloading and a large pool sustain high bandwidth transmission at a central synapse. Nature 439:983-987.

Schneggenburger R, Forsythe ID (2006) The calyx of Held. Cell Tissue Res 326:311-337.

Schneggenburger R, Meyer AC, Neher E (1999) Released fraction and total size of a pool of immediately available transmitter quanta at a calyx synapse. Neuron 23:399-409.

Sonntag M, Englitz B, Kopp-Scheinpflug C, Rübsamen R (2009) Early postnatal development of spontaneous and acoustically evoked discharge activity of principal cells of the medial nucleus of the trapezoid body: an in vivo study in mice. J Neurosci 29:9510-9520.

Taschenberger H, von Gersdorff H (2000) Fine-tuning an auditory synapse for speed and fidelity: developmental changes in presynaptic waveform, EPSC kinetics, and synaptic plasticity. J Neurosci 20:9162-9173.
Taschenberger H, Leão RM, Rowland KC, Spirou GA, von Gersdorff H (2002) Optimizing synaptic architecture and efficiency for high-frequency transmission. Neuron 36:1127-1143.

Taschenberger H, Scheuss V, Neher E (2005) Release kinetics, quantal parameters and their modulation during short-term depression at a developing synapse in the rat CNS. J Physiol 568:513-537.

Tolnai S, Englitz B, Scholbach J, Jost J, Rübsamen R (2009) Spike transmission delay at the calyx of Held in vivo: rate dependence, phenomenological modeling, and relevance for sound localization. J Neurophysiol 102:1206-1217.

Tritsch NX, Bergles DE (2010) Developmental regulation of spontaneous activity in the mammalian cochlea. J Neurosci 30:1539-1550.

Tritsch NX, Yi E, Gale JE, Glowatzki E, Bergles DE (2007) The origin of spontaneous activity in the developing auditory system. Nature 450:50-55.

Tritsch NX, Rodríguez-Contreras A, Crins TT, Wang HC, Borst JG, Bergles DE (2010) Calcium action potentials in hair cells pattern auditory neuron activity before hearing onset. Nat Neurosci 13:1050-1052.

Uziel A, Romand R, Marot M (1981) Development of cochlear potentials in rats. Audiology 20:89-100.

van Looij MA, Liem SS, van der Burg H, van der Wees J, De Zeeuw CI, van Zanten BG (2004) Impact of conventional anesthesia on auditory brainstem responses in mice. Hear Res 193:75-82.

Varela JA, Sen K, Gibson J, Fost J, Abbott LF, Nelson SB (1997) A quantitative description of short-term plasticity at excitatory synapses in layer $2 / 3$ of rat primary visual cortex. J Neurosci 17:7926-7940.

von Gersdorff H, Borst JG (2002) Short-term plasticity at the calyx of Held. Nat Rev Neurosci 3:53-64.

von Gersdorff H, Schneggenburger R, Weis S, Neher E (1997) Presynaptic depression at a calyx synapse: the small contribution of metabotropic glutamate receptors. J Neurosci 17:8137-8146.

Walsh EJ, McGee J (1987) Postnatal development of auditory nerve and cochlear nucleus neuronal responses in kittens. Hear Res 28:97-116.

Wang LY, Kaczmarek LK (1998) High-frequency firing helps replenish the readily releasable pool of synaptic vesicles. Nature 394:384-388.

Wimmer VC, Horstmann H, Groh A, Kuner T (2006) Donut-like topology of synaptic vesicles with a central cluster of mitochondria wrapped into membrane protrusions: a novel structure-function module of the adult calyx of Held. J Neurosci 26:109-116.

Wong AY, Graham BP, Billups B, Forsythe ID (2003) Distinguishing between presynaptic and postsynaptic mechanisms of short-term depression during action potential trains. J Neurosci 23:4868-4877.

Woolf NK, Ryan AF (1988) Contributions of the middle ear to the development of function in the cochlea. Hear Res 35:131-142.

Wu LG, Borst JG (1999) The reduced release probability of releasable vesicles during recovery from short-term synaptic depression. Neuron 23:821-832.

Wu SH, Oertel D (1987) Maturation of synapses and electrical properties of cells in the cochlear nuclei. Hear Res 30:99-110.

$\mathrm{Xu} \mathrm{J,} \mathrm{Wu} \mathrm{LG} \mathrm{(2005)} \mathrm{The} \mathrm{decrease} \mathrm{in} \mathrm{the} \mathrm{presynaptic} \mathrm{calcium} \mathrm{current} \mathrm{is} \mathrm{a}$ major cause of short-term depression at a calyx-type synapse. Neuron 46:633-645.

Yang YM, Fedchyshyn MJ, Grande G, Aitoubah J, Tsang CW, Xie H, Ackerley CA, Trimble WS, Wang LY (2010) Septins regulate developmental switching from microdomain to nanodomain coupling of $\mathrm{Ca}^{2+}$ influx to neurotransmitter release at a central synapse. Neuron 67:100-115. 